\title{
Mechanisms of regulatory $T$ cell infiltration in tumors: implications for innovative immune precision therapies
}

\author{
Shohei Koyama, ${ }^{1,2}$ Hiroyoshi Nishikawa (D) ${ }^{1,3}$
}

To cite: Koyama S, Nishikawa H. Mechanisms of regulatory T cell infiltration in tumors: implications for innovative immune precision therapies. Journal for ImmunoTherapy of Cancer 2021;9:e002591. doi:10.1136/jitc-2021-002591

Accepted 11 July 2021

Check for updates

(C) Author(s) (or their employer(s)) 2021. Re-use permitted under CC BY. Published by BMJ.

${ }^{1}$ Division of Cancer Immunology, Research Institute/Exploratory Oncology Research and Clinical Trial Center (EPOC), National Cancer Center, Tokyo/Chiba, Japan

${ }^{2}$ Department of Respiratory Medicine and Clinical Immunology, Osaka University Graduate School of Medicine, Osaka, Japan

${ }^{3}$ Department of Immunology, Nagoya University Graduate School of Medicine, Nagoya, Japan

Correspondence to Dr Hiroyoshi Nishikawa; hnishika@ncc.go.jp

\section{ABSTRACT}

With the broad application of cancer immunotherapies such as immune checkpoint inhibitors in multiple cancer types, the immunological landscape in the tumor microenvironment (TME) has become enormously important for determining the optimal cancer treatment. Tumors can be immunologically divided into two categories: inflamed and non-inflamed based on the extent of immune cell infiltration and their activation status. In general, immunotherapies are preferable for the inflamed tumors than for non-inflamed tumors. Regulatory T cells (Tregs), an immunosuppressive subset of $\mathrm{CD} 4^{+} \mathrm{T}$ cells, play an essential role in maintaining self-tolerance and immunological homeostasis. In tumor immunity, Tregs compromise immune surveillance against cancer in healthy individuals and impair the antitumor immune response in tumor-bearing hosts. Tregs, therefore, accelerate immune evasion by tumor cells, leading to tumor development and progression in various types of cancer. Therefore, Tregs are considered to be a crucial therapeutic target for cancer immunotherapy. Abundant Tregs are observed in the TME in many types of cancer, both in inflamed and non-inflamed tumors. Diverse mechanisms of Treg accumulation, activation, and survival in the TME have been uncovered for different tumor types, indicating the importance of understanding the mechanism of Treg infiltration in each patient when selecting the optimal Treg-targeted therapy. Here, we review recent advances in the understanding of mechanisms leading to Treg abundance in the TME to optimize Treg-targeted therapy. Furthermore, in addition to the conventional strategies targeting cell surface molecules predominantly expressed by Tregs, reagents targeting molecules and signaling pathways specifically employed by Tregs for infiltration, activation, and survival in each tumor type are illustrated as novel Treg-targeted therapies. The effectiveness of immune precision therapy depends on conditions in the TME of each cancer patient.

\section{INTRODUCTION}

The interaction between tumor cells and immune cells plays an important role in tumor development and progression. Tumor cells with low immunogenicity are selected by immunological pressure (immune selection) and immunosuppressive molecules and cells are employed to hinder antitumor immunity (immune escape), which is the basic principle of cancer immunoediting. ${ }^{1}$ Cancer immunotherapies, such as immune checkpoint inhibitors that can resurge impaired antitumor immune responses during tumor development and progression, have been widely used in multiple cancer types clinically. ${ }^{2}$ However, their therapeutic efficacy is limited because of immune evasion mechanisms other than checkpoint molecules, such as immunosuppressive cells in the tumor microenvironment (TME) and disrupted antigen presentation of tumor-specific antigens, which originate from gene alterations in tumor cells. Gene alterations in tumor cells modulate cell-intrinsic signaling involved in tumor cell proliferation, secretion of immunomodulatory molecules for immune cell infiltration and function, and presentation of non-self tumor-specific antigens stemming from gene alterations shape the immunological landscape, leading to tumors with or without inflammation: inflamed versus non-inflamed of tumors. Inflamed tumors and non-inflamed tumors are also called hot and cold tumors, respectively. Non-inflamed tumors include the immune excluded type and the immune desert type. Immune cells are present at the invasive margins of the tumors in the immune excluded type. Immune cells are hardly detected throughout tumors in the immune desert type. Concisely, this review focuses on inflamed and non-inflamed tumors.

Regulatory $\mathrm{T}$ cells (Tregs) are a distinctive lineage of $\mathrm{CD}^{+} \mathrm{T}$ cells that suppress the immune system. They restrain immune responses against self-antigens in autoimmunity and excessive immune-mediated inflammation during infection. ${ }^{3}$ Tregs function as major immunosuppressive cells in the context of tumor immunity. They efficiently infiltrate and adapt to the TME and dampen antitumor immune responses. Tregs promote tumor cell proliferation through inhibiting antigenpresenting cells (APCs), consuming a critical cytokine for effector $\mathrm{T}$ cell activation and 
function, and producing immunosuppressive humoral factors, resulting in the development of an immunosuppressive TME. ${ }^{4-7}$ Therefore, while abundant cytotoxic $\mathrm{CD}^{+} \mathrm{T}$ cells (CTLs) among tumor-infiltrating lymphocytes (TILs) are generally correlated with favorable prognosis and clinical response to immunotherapies, a higher proportion of Tregs among TILs is associated with poor prognosis and clinical response to immunotherapies. ${ }^{8-10}$ An abundance of Tregs is frequently observed in the TME with multiple types of cancer, both in inflamed and non-inflamed tumors, yet, the mechanisms leading to Treg abundance remain to be elucidated. Recent studies revealed that multiple mechanisms are involved in Treg infiltration, activation, and survival in the TME, which varies by tumor type. Since the immunological characteristics of the TME is closely linked to gene alterations in tumor cells, understanding the mechanisms leading to Treg abundance in each patient becomes critical for developing Treg-targeted therapy. In this review, we illustrate recent findings regarding the mechanisms leading to Treg abundance in the TME and how Tregs suppress antitumor immune responses. We also discuss which Tregtargeting therapies could be optimal from the perspective of immune/genomic precision medicine.

\section{CHARACTERISTICS AND PHENOTYPES OF TREGS}

Forkhead box P3 (FOXP3) is a master regulatory transcription factor for generating the immunosuppressive $\mathrm{CD}^{+}$Treg lineage, which maintains self-tolerance and immunological homeostasis. ${ }^{11-14}$ Tregs consist of two distinct subsets based on where they are generated. Thymic Tregs (tTregs), also called natural Tregs (nTregs), originate from the thymus. Peripheral Tregs (pTregs), also called induced Tregs (iTregs), are derived from naive $\mathrm{CD} 4^{+} \mathrm{T}$ cells in the periphery under certain conditions, such as $\mathrm{T}$ cell receptor (TCR) stimulation in the presence of cytokines such as tumor growth factor beta (TGF- $\beta$ ), interleukin (IL)-2, and retinoic acid. ${ }^{15-18}$ In contrast to tTregs, pTregs are unstable and convert to conventional FOXP3 ${ }^{-} \mathrm{CD}^{+} \mathrm{T}$ cells (Tconvs) with the loss of FOXP3 expression. DNA hypomethylation in the Foxp3 conserved noncoding sequences 2 (CNS2) locus, where some transcription factors including signal transducer and activator of transcription 5 (STAT5) and cyclic AMP (cAMP) response element-binding protein interact and induce FOXP3 expression, is observed in tTregs but not in pTregs, which contributes to the stability of FOXP3 expression in tTregs. ${ }^{19}$ Although both tTregs and pTregs are found in tumors and restrain antitumor immune responses, ${ }^{20}{ }^{21}$ details about the function and stability of each Treg subset in the TME remain to be elucidated.

While TCR stimulation in the presence of TGF- $\beta$ easily induces FOXP3 expression in human naive $\mathrm{T}$ cells in vitro, unlike in mice, these FOXP3-expressing cells fail to gain immunosuppressive function. Instead, they produce proinflammatory cytokines on stimulation. ${ }^{22}$ Thus, we need to carefully understand how TGF- $\beta$-induced
$\mathrm{FOXP3}^{+} \mathrm{T}$ cells in mice and humans differ: In this review, we mainly describe human $\mathrm{FOXP}^{+} \mathrm{T}$ cells. Accordingly, $\mathrm{FOXP}^{+} \mathrm{CD}^{+} \mathrm{T}$ cells in humans include populations that are heterogeneous in phenotype and function. Therefore, specific markers to discriminate Tregs from Tconvs are indispensable for evaluating human $\mathrm{FOXP}^{+} \mathrm{CD}^{+} \mathrm{T}$ cells. A classification of human $\mathrm{FOXP} 3^{+} \mathrm{CD} 4^{+} \mathrm{T}$ cells based on FOXP3 (and/or CD25) and CD45RA expression was proposed by Dr. Sakaguchi's group: Fraction 1 (Fr. 1), naive Tregs defined as FOXP $3^{\text {low }}\left(\mathrm{CD} 25^{\text {low }}\right) \mathrm{CD}_{4} 5 \mathrm{RA}^{+}$cells; Fraction 2 (Fr. 2), effector Tregs (eTregs), defined as FOXP3 $3^{\text {high }}\left(\mathrm{CD} 25^{\text {high }}\right) \mathrm{CD} 45 \mathrm{RA}^{-}$cells; and Fraction 3 (Fr. $3)$, non-Tregs, defined as FOXP3 $3^{\text {low }}\left(\mathrm{CD}_{2} 5^{\text {low }}\right) \mathrm{CD} 45 \mathrm{RA}^{-}$ cells $^{23}$ (figure 1A). Naive Tregs (Fr. 1) that recently left the thymus have weak immunosuppressive activity. Once naive Tregs (Fr. 1) receive TCR stimulation, they differentiate into eTregs (Fr. 2), which have strong immunosuppressive activity. It has been recently shown that Tregs in the TME harbor a unique TCR repertoire. Tregs and Tconvs, which recognize tumor-specific antigens, ${ }^{21}$ have different TCR repertoires. These findings suggest that the differentiation and expansion of eTregs in the TME are mainly induced by stimulation from immunogenic self-antigens specific for tTregs in tumor cells as Tregs recognize immunogenic self-antigens. ${ }^{24}{ }^{25}$ Non-Tregs (Fr. 3) do not have immunosuppressive properties. Instead, they can produce inflammatory cytokines, such as interferon (IFN) $-\gamma$ and IL-17. ${ }^{23}$ In the TME of melanoma, non-small cell lung cancer (NSCLC), and gastric cancer, eTregs are heavily infiltrated and account for 20\%-60\% of $\mathrm{CD} 4{ }^{+} \mathrm{T}$ cells ${ }^{26}$. tTregs can also be detected in the peripheral blood. The proportion of tTregs among $\mathrm{CD} 4^{+}$ $\mathrm{T}$ cells declines with age: $4 \%-10 \%$ in cord blood, $1 \%-4 \%$ in young adults, and $0.5 \%-1.5 \%$ in healthy elderly individuals. ${ }^{27}$ By contrast, the proportion of eTregs increases with age: $0 \%-0.5 \%$ in cord blood, $1 \%-2.5 \%$ in young adults, and $1 \%-4 \%$ in elderly health individuals. ${ }^{23}$

\section{MECHANISMS THROUGH WHICH TREGS SUPPRESS ANTITUMOR IMMUNE RESPONSES}

Tregs hinder antitumor immune responses through multiple mechanisms (figure 1B). In Tregs, coinhibitory receptor cytotoxic $\mathrm{T}$ lymphocyte antigen 4 (CTLA-4) disrupts costimulatory signaling via $\mathrm{CD} 80 / \mathrm{B} 7-1$ and CD86/B7-2 in APCs and the co-stimulatory receptor CD28 in effector $\mathrm{T}$ cells through higher affinity binding of CTLA-4 to CD80/B7-1 and CD86/B7-2 than CD28 to CD80/B7-1 and CD86/B7-2. When these co-stimulatory molecules interact with CTLA-4, they are captured from APCs such as dendritic cells (DCs) via trans-endocytosis, resulting in impaired costimulation via CD28 ${ }^{28}$ In addition, leukocyte function-associated antigen 1 in Tregs forms long-lasting aggregates with DCs as a result of the disrupted interaction between DCs and effector T cells. ${ }^{29}$

IL-2 is an essential cytokine for the survival of both Tregs and effector T cells. Compared with effector T cells, Tregs can dominantly access IL-2 with a higher affinity 
A

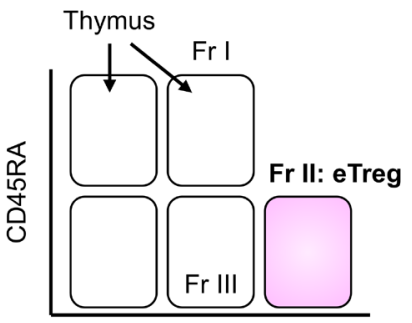

FOXP3

B

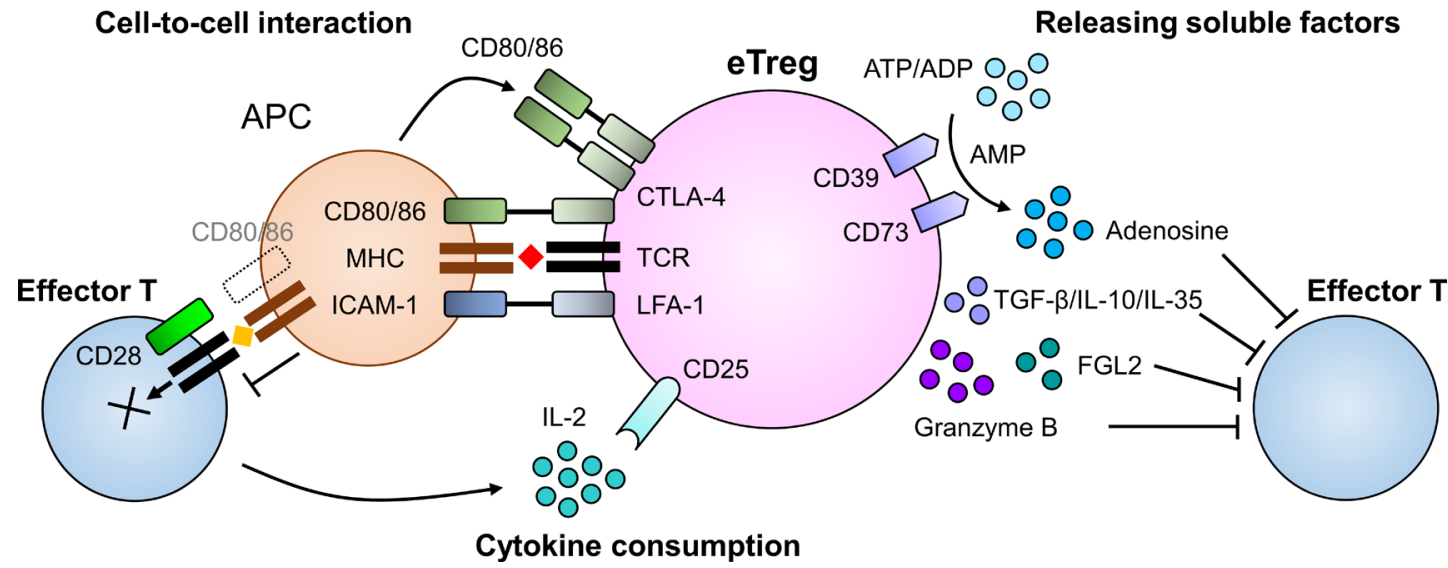

Figure 1 Mechanisms of immunosuppression by eTregs. (A) FOXP3 ${ }^{+} C D 4^{+} T$ cells can be classified into three fractions based on FOXP3 (and/or CD25) and CD45RA expression levels: fraction 1 (Fr. 1), naive Tregs defined as FOXP3 ${ }^{\text {low }}\left(C^{2} 25^{\text {low }}\right) C$ D 45RA ${ }^{+}$ cells; fraction 2 (Fr. 2), eTregs, defined as FOXP3 ${ }^{\text {high }}\left(\mathrm{CD} 25^{\text {high }}\right)$ CD45RA- $^{-}$cells; and fraction 3 (Fr. 3), non-Tregs, defined as FOXP3 ${ }^{\text {low }}\left(\mathrm{CD}^{2} 5^{\text {low }}\right) \mathrm{CD} 45 \mathrm{RA}^{-}$cells. Naive Tregs (Fr. 1) that recently left the thymus have weak immunosuppressive activity. Once naive Tregs (Fr. 1) receive TCR stimulation, they differentiate into eTregs (Fr. 2), which have strong immunosuppressive activity. Non-Tregs (Fr. 3) do not have immunosuppressive activity. (B) Coinhibitory receptor cytotoxic T lymphocyte antigen 4 (CTLA-4) in Tregs inhibits costimulatory signaling via CD80/B7-1 and CD86/B7-2 in antigen presenting cells (APCs) due to its high affinity binding to CD80/B7-1 and CD86/B7-2. when these costimulatory molecules interact with CTLA-4, they are captured from APCs by transendocytosis. Compared with effector T cells, Tregs harbor receptors with higher affinity for IL-2: much higher CD25 expression in Tregs than in effector T cells. This provides Tregs with a competitive advantage in utilizing the limited amount of IL-2 in the TME. Tregs produce TGF- $\beta$, IL-10, and IL-35 for immunosuppression. TGF- $\beta$ reduces the cytotoxic function of effector T cells. Fgl2 secreted by Tregs binds to FcyRIIB in CD8 ${ }^{+} \mathrm{T}$ cells and leads to their apoptosis. CD39 and CD73 expressed on the cell surface of Tregs act as ectonucleotidases that hydrolyze ATP or ADP to AMP and AMP to adenosine, respectively. Adenosine suppresses effector T cells. eTregs, effector Tregs; Fc $\gamma R$ IIIB, Fc fragment of IgG receptor llb; FOXP3, Forkhead box P3; IL-10, interleukin 10; TCR, T cell receptor; TGF- $\beta$, tumor growth factor beta; TME, tumor microenvironment; Tregs, regulatory $\mathrm{T}$ cells.

receptor that consists of $\alpha(\mathrm{CD} 25), \beta$ (CD122), and $\gamma$ (CD132) subunits. ${ }^{30}$ Although TCR and IL-2 signaling are necessary for the immunosuppressive activity of Tregs, ${ }^{31} 32$ Tregs themselves are not able to produce IL-2 because FOXP3 suppresses the transcription of IL-2. ${ }^{33} 34$ By contrast, FOXP3 induces the expression of CD25, a highaffinity receptor for IL-2. ${ }^{33}$ Tregs harbor much higher CD25 expression than effector $\mathrm{T}$ cells, which provides Tregs with a competitive advantage in utilizing the limited amount of IL-2 in the TME. ${ }^{35}$ As a result, there is more accumulation of Tregs than effector T cells in the TME.

In addition, secretion of immunosuppressive molecules including immunosuppressive cytokines from Tregs also suppresses antitumor immunity. Tregs produce TGF- $\beta$, IL-10, and IL-35 for immunosuppression. TGF- $\beta$ reduces the cytotoxic function of NK cells and CTLs ${ }^{36}$ and induces the conversion of NK cells into type 1 innate lymphoid cells in the TME, which fail to control tumor growth and metastasis. ${ }^{37}$ TGF- $\beta$ signaling also drives the trans-differentiation of Th17 cells into Tregs, resulting in the development of immune tolerance and immunosuppression in the TME. ${ }^{38}$ TGF- $\beta$ can be produced by both immune and non-immune cells. The function of Treg cell-derived TGF- $\beta$ remains controversial. While several studies have implicated TGF- $\beta$ as playing an important role in immunosuppression by Tregs, ${ }^{39-41}$ other studies have shown that Treg-derived TGF- $\beta 1$, the major subtype of TGF- $\beta$, is largely redundant in immune regulation. ${ }^{4243}$ Further investigation is warranted to clarify the detailed role of Treg-derived TGF- $\beta 1$ in vivo.

Tregs are a major source of the immunomodulatory cytokine IL-10 in the TME. Treg-specific ablation of IL-10 in a murine model exhibited tissue-specific inflammation in the colon, lung, and skin, but not in the systemic 
inflammatory phenotype. These findings indicate that Treg-derived IL-10 might be important for regulating inflammation at environmental interfaces. ${ }^{44}$ Although IL-10 exerts various effects in the TME, its immunosuppressive effect can be enhanced with IL-35, which is also produced by Tregs. In a murine melanoma model, IL-35-producing Tregs accumulated in the TME and disrupted antigen-specific effector $\mathrm{T}$ cell activation and their effector function via falling them into the exhaustion. ${ }^{45}$ The expression pattern and immunosuppressive roles of IL-10 and IL-35 in tumor-infiltrating Tregs were different in tumor-bearing mice and patients with NSCLC. ${ }^{46}$ Tumor growth was slower in mice with IL-35IL-10 $10^{-/}$Tregs compared with those with either IL- $35^{-/}$or IL-10 $0^{-/}$Tregs. Interestingly, IL-35 and IL-10 have different immunomodulatory functions. IL-35-producing Tregs promote the exhaustion of effector T cells whereas IL-10producing Tregs inhibit the cytotoxic effector function of effector T cells. ${ }^{45} 46$

Fibrinogen-like protein 2 (FGL2) is produced by Tregs. It binds to the Fc fragment of IgG receptor IIb (Fc $\gamma \mathrm{RIIB}$ ) receptor, which transduces inhibitory signaling via an immunoreceptor tyrosine-based inhibitory motif. Because Fc $\gamma$ RIIB can be induced in activated $\mathrm{CD}^{+} \mathrm{T}$ cells in the TME, FGL2 secreted by Tregs binds to Fc $\gamma$ RIIB in CD8 ${ }^{+} \mathrm{T}$ cells and leads to their apoptosis through caspase 3 and 7 induction. Mice with Fc $\gamma$ RIIB-deficient $\mathrm{CD}^{+}{ }^{+} \mathrm{T}$ cells have less tumor growth than control mice, ${ }^{47}$ suggesting that Tregs enable suppression of $\mathrm{CD}^{+} \mathrm{T}$ cells through Fc $\gamma$ RIIB. Granzyme B produced by cytotoxic cells, such as NK cells and CTLs, is an important effector molecule for killing target cells. However, a subset of Tregs in the TME produce granzyme B and kill effector cytotoxic cells, which can also be involved in Treg-mediated suppression of antitumor immune responses. ${ }^{40}$

CD39 and CD73 expressed on the cell surface of Tregs act as ectonucleotidases that hydrolyze ATP or ADP to AMP and AMP to adenosine, respectively. ${ }^{48}$ ATP hydrolysis by CD39 and CD73 produces adenosine and suppresses effector T cells. ${ }^{490}$ Although ATP is strictly retained within cells under normal conditions, intracellular ATP can be released from necrotic or inflammatory cells in tumors via vesicular exocytosis and membrane transporters. ${ }^{51}$ There are two classes of P2 purinergic receptors for ATP: P2XR and P2YR. While both are expressed by APCs such as DCs and monocytes, lymphocytes only express P2XR. ${ }^{48}$ ATP sensing by the receptors P $2 \times 1 \mathrm{R}, \mathrm{P} 2 \times 4 \mathrm{R}, \mathrm{P} 2 \times 5 \mathrm{R}$, and $\mathrm{P} 2 \times 7 \mathrm{R}$ activates effector $\mathrm{T}$ cells, which induces apoptosis in Tregs when ATP interacts with $\mathrm{P} 2 \times 7 \mathrm{R}^{52} 53$. Adenosine is recognized by two independent receptors: Adora2a (A2a) and Adora2b (A2b). The A2a receptor is constitutively expressed by $\mathrm{T}$ cells and has higher affinity for adenosine than the A2b receptor. ${ }^{54}$ When these receptors are stimulated with adenosine, cAMP is generated through adenylyl cyclase, which triggers protein kinase $\mathrm{A}$ and inhibits Tconvs proliferation and function. ${ }^{55}$ In murine tumor models, CD39 and CD73 expressed by Tregs reduce ATP and produce adenosine, which suppresses antitumor effector $\mathrm{T}$ cells. Tumor growth was suppressed in mice with either $\mathrm{CD} 39^{-/}$or $\mathrm{CD} 73^{-/-}$Tregs compared with wild-type mice. ${ }^{567}$ When Tregs undergo apoptosis in the TME, apoptotic Tregs release a large amount of adenosine via ectonucleotidases, resulting in far stronger suppression of antitumor immunity. ${ }^{58}$

Through the multiple immunosuppressive mechanisms mentioned above, Tregs play a major role in resistance to PD-1 blockade therapy in many types of cancer. We have recently reported that PD- $1^{+}$Tregs could be activated by PD-1 blockade therapy with enhanced TCR and costimulatory signals, leading to PD- ${ }^{+}$Tregs with robust immunosuppressive function. ${ }^{59}$ Accordingly, the balance between PD- $1^{+} \mathrm{CD}^{+} \mathrm{T}$ cells and PD- $1^{+}$eTregs is a novel biomarker for predicting the therapeutic effect of PD-1 blockade. ${ }^{59}$ Moreover, eTregs that express PD-1 could contribute to hyperprogressive disease after PD-1 blockade monotherapy in certain patients, particularly patients with liver metastases. ${ }^{60}$ Thus, patients with a high proportion of PD- $1^{+}$eTregs in the TME might need combination treatment that includes Treg-targeted therapy in addition to PD-1 blockade. Recently, liver metastases were shown to induce antigen-specific $\mathrm{T}$ cell suppression of systemic immunity against extrahepatic tumors in a preclinical model. Treg depletion reversed liver tumor-associated systemic immunosuppression, resulting in the accumulation of $\mathrm{CD}^{+} \mathrm{T}$ cells in extrahepatic tumors. Therefore, Tregs could contribute to systemic suppression of antitumor immunity in tumor-bearing hosts, particularly hosts with liver metastases. ${ }^{61}$ The detailed mechanisms underlying the systemic suppression of antitumor immunity by liver metastases are necessary to be elucidated.

\section{MECHANISMS LEADING TO TREG ABUNDANCE IN THE TME Chemokine- and cytokine-dependent infiltration and conversion}

Tregs have multiple chemokine receptors. Chemokine gradients such as CCR4-CCL17/22, ${ }^{62}$ CCR5-CCL5, ${ }^{63}$ CCR8-CCL1, ${ }^{64}$ and CCR10-CCL28 ${ }^{65}$ can be involved in recruiting Tregs into the TME (figure 2). Tregs are generally recruited to sites of inflammation via the local cytokine milieu and are therefore detected with inflammatory cells, such as $\mathrm{CD}^{+} \mathrm{T}$ cells and myeloid cells in the inflamed tumors. ${ }^{66}$ In the inflamed tumors, inflammatory cells produce Treg-recruiting chemokines such as CCL22. ${ }^{67} 68$ CCR4, which is highly expressed by activated Tregs, has been implicated in their trafficking to nonlymphoid organs and tumors. For instance, CCR4-dependent and CCR5-dependent Treg infiltration is reportedly involved in breast cancer and lymphoma ${ }^{69-71}$ and pancreatic and squamous cell carcinoma, ${ }^{63} 72$ respectively. CCR4 is also needed for lymph node egress of activated Tregs that infiltrate the nascent TME in mouse melanoma with $\mathrm{BRAF}^{\mathrm{V} 600 \mathrm{E}} \cdot{ }^{73} \mathrm{CCR}^{+}$Tregs are recruited by CCR 8 ligands, such as CCL1 and CCL18 ${ }^{74}$ to inflammatory sites like the TME. CCL1 not only recruits CCR $8^{+}$Tregs to tumors but also induces STAT3-dependent upregulation of FOXP3, 

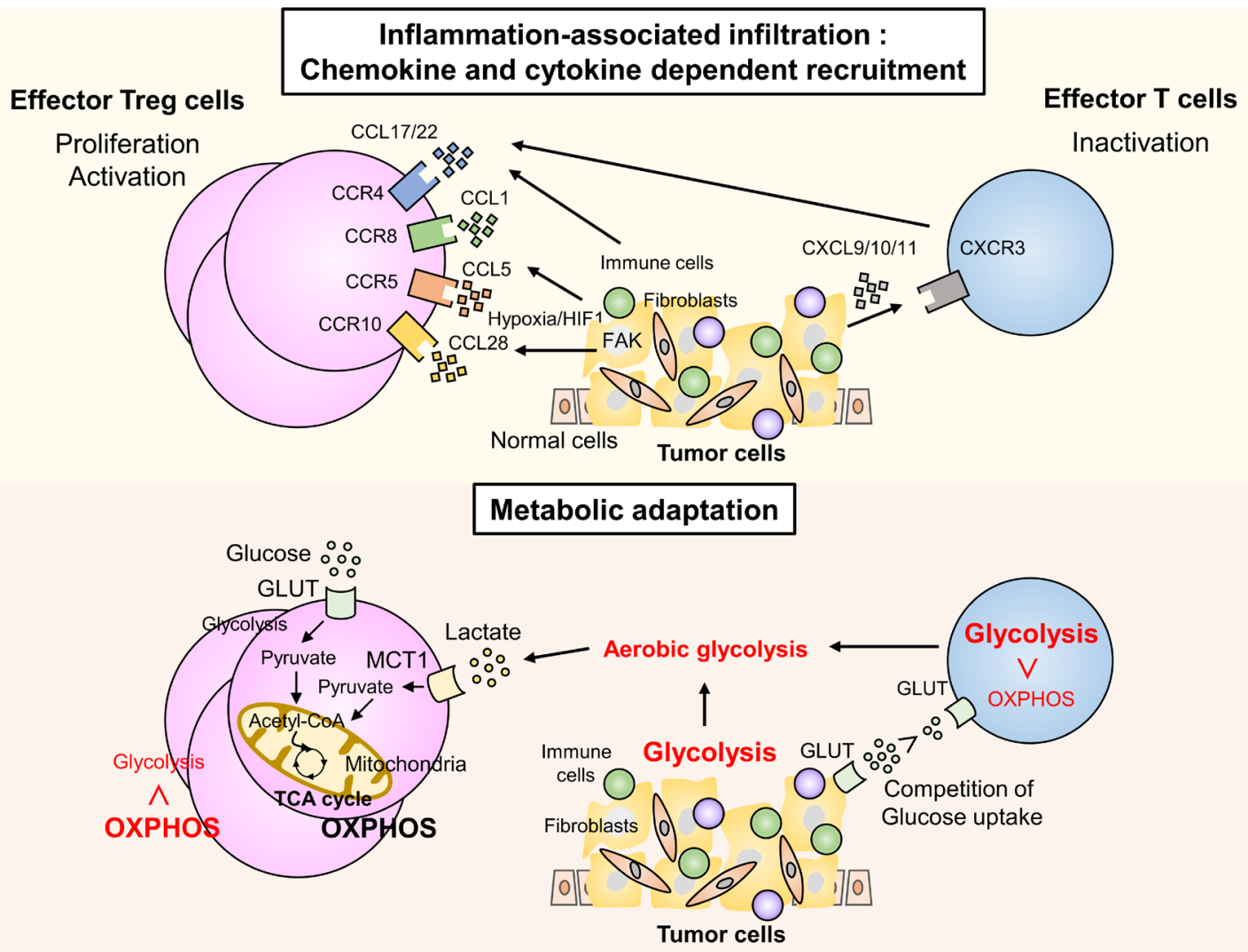

Figure 2 Mechanisms leading to Treg infiltration and adaptation in the inflamed TME. Inflammation-associated infiltration: chemokine and cytokine dependent recruitment. Tregs possess multiple chemokine receptors. Chemokine gradients such as CCR4-CCL17/22, CCR8-CCL1, CCR5-CCL5, and CCR10-CCL28 are involved in recruiting Tregs into the TME. Hyperactivation of focal adhesion kinase (FAK) is correlated with Treg infiltration and $C D 8^{+} \mathrm{T}$ cell exclusion via regulation of the production of chemokines such as CCL5 by tumor cells. Tumor hypoxia induces the expression of CCL28 and promotes the recruitment of Tregs via CCR10. activated CD8 ${ }^{+} \mathrm{T}$ cells also produce CCL17/22 that recruit Tregs. On the other hand, chemokine gradients such as CXCR3-CXCL9/10/11 are involved in CD8 ${ }^{+} \mathrm{T}$ cell recruitment. Metabolic adaptation. Effector $\mathrm{T}$ cells and Tregs employ different metabolic system in normal versus inflammatory conditions. TCR stimulation provokes a specific metabolic program through the PI3K-mTOR signaling pathway, leading to increased uptake of glucose through glucose transporter (GLUT) to enhance aerobic glycolysis. Activated effector T cells shift their metabolic program from oxidative phosphorylation (OXPHOS) to aerobic glycolysis. Metabolic reprogramming in tumor cells changes the TME into a nutrient-restricted, lactate-rich, and hypoxic environment, which is unfavorable for the survival and function of effector T cells. FOXP3 plays an essential role in this distinct metabolic program of Tregs by suppressing glycolysis, promoting OXPHOS, and enabling the use of lactate through monocarboxylate transporter 1 (MCT1) as an energy source. While tumor-infiltrating non-Tregs convert pyruvate to lactate to maintain glycolysis, Tregs in the TME convert pyruvate to acetyl-CoA in the mitochondria to trigger the tricarboxylic acid (TCA) cycle, which provides a survival benefit to Tregs over effector T cells in the low-glucose, high-extracellular lactate TME. mTOR, mammalian target of rapamycin; PI3K phosphoinositide 3-kinase; TME, tumor microenvironment; Tregs, regulatory T cells.

CD39, and IL-10, which are crucial for Treg suppression, resulting in enhanced immunosuppressive activity in Tregs. ${ }^{75}$ Among a series of cytokine and chemokine receptors, CCR8 was most notably upregulated only in tumorinfiltrating Tregs in human breast cancer compared with normal tissue-resident Tregs, ${ }^{76}$ indicating that CCR8 is a promising therapeutic target for Tregs in the TME without eliciting systemic autoimmunity. Tumor hypoxia induces the expression of CCL28 and promotes the recruitment of Tregs through CCR10 in ovarian cancer. Tumor-infiltrating CCR10 $0^{+}$Tregs also produce vascular endothelial growth factor A (VEGFA) and establish a VEGFA-rich TME, ${ }^{65}$ which further promotes an immunosuppressive TME via VEGFA recruitment of Tregs. ${ }^{77}$
While the inflamed tumors commonly contain Tregs, abundant Tregs are sometimes detected in a subset of non-inflamed tumors, suggesting that mechanisms other than inflammation-associated infiltration are involved in recruiting Treg to the TME (figure 3). We discovered certain gene alterations that could modify tumor cells to produce chemokines through modulating downstream signaling pathways. Gain-of-function EGFR mutations found in lung adenocarcinoma ${ }^{78}$ are generally associated with non-inflamed tumors, but abundant Tregs have been detected in these tumors without the presence of inflammatory cells. EGFR mutations decrease CXCL10 production through IFN regulatory factor 1 (IRF1) inhibition, which negatively affects CXCR3-dependent $\mathrm{CD}^{+} \mathrm{T}$ cell 


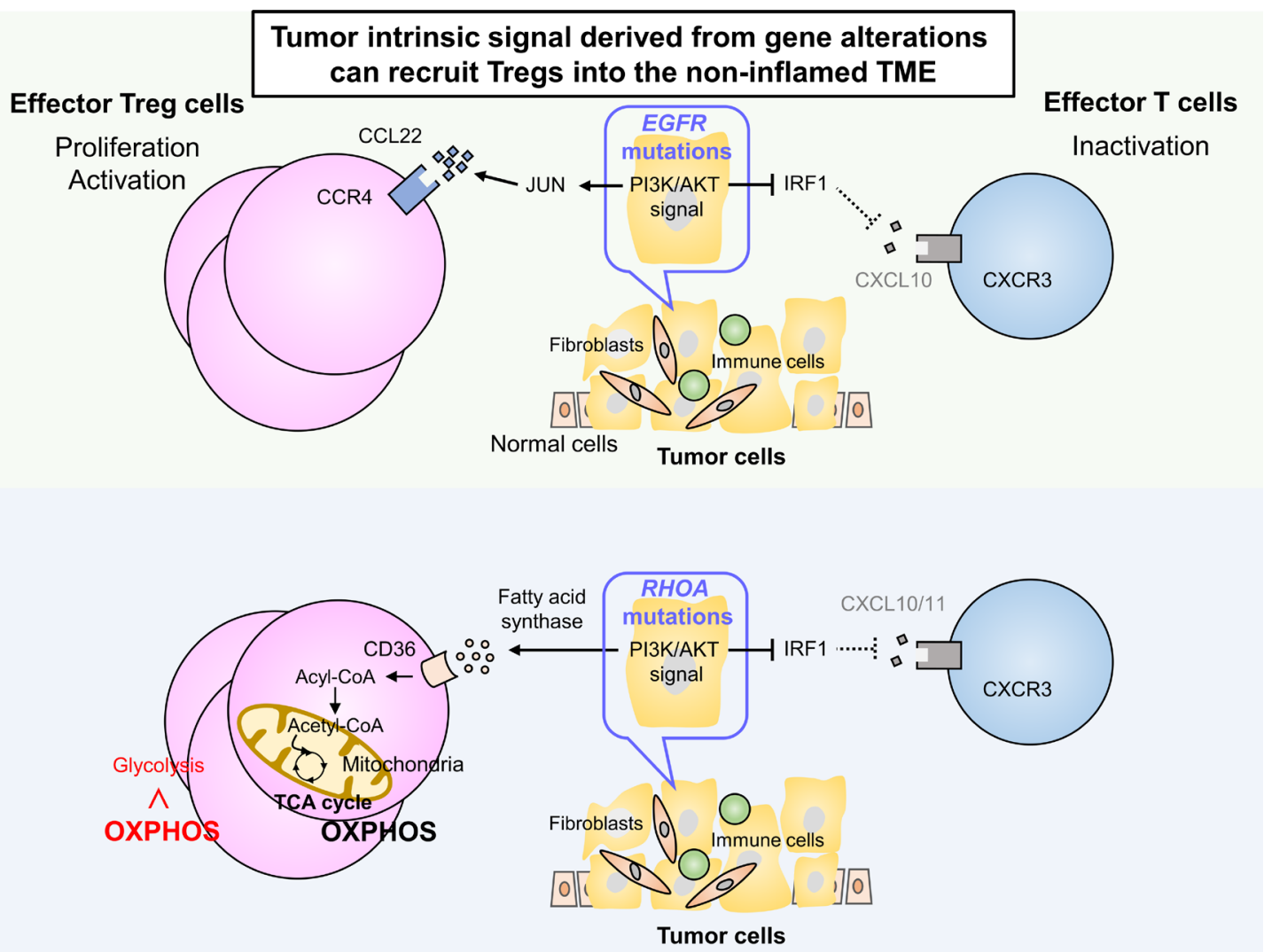

Figure 3 Mechanisms leading to Treg infiltration and adaptation in the non-inflamed TME. Tumor cell intrinsic signaldependent infiltration. Certain gene alterations can modify the chemokine profile in tumor cells by modulating downstream signaling pathways. EGFR mutations in lung adenocarcinoma reduce CXCL10 production through interferon regulatory factor 1 (IRF1) inhibition. CCL22 production is increased via JUN induction, leading to CCR4-dependent Treg infiltration in the TME. In gastric cancers with RHOA mutations, CXCL10/11 levels are reduced through IRF1 suppression. RHOA mutations in gastric cancer produce large amounts of fatty acids through upregulation of fatty acid synthase (FASN) compared with tumors without RHOA mutations, leading to more Tregs and fewer effector T cells in the TME. Fatty acids produced in the TME can be used by Tregs as an energy source. Tregs use mechanisms in the fatty acid metabolism, such as upregulating the fatty acid transporter CD36, to adapt to the fatty acid-rich TME. FAK, focal adhesion kinase; GLUT, glucose through glucose transporter; OXPHOS, oxidative phosphorylation; PI3K, phosphoinositide 3-kinase; TME, tumor microenvironment; Tregs, regulatory T cells.

recruitment to the TME. Moreover, CCL22 production is increased via $J U N$ induction in downstream signaling of EGFR, leading to CCR4-dependent Treg infiltration into the TME. ${ }^{79}$ This mechanism accounts for why large numbers of Tregs accumulate in non-inflamed tumors with EGFR mutations. A similar phenotype was also observed in gastric cancers with RHOA Y42 mutation, which is lossof-function mutation that reduces CXCL10/11 levels through IRF1 suppression. ${ }^{80}$ In addition, hyperactivation of focal adhesion kinase is correlated with Treg infiltration and $\mathrm{CD}^{+} \mathrm{T}$ cell exclusion through regulating chemokine production, including CCL5 production, by tumor cells. ${ }^{81} 82$

The specific cytokine and growth factor profile of the TME could induce the conversion of Tconvs to Tregs, which may contribute to the infiltration of Tregs into the TME. Previous studies have reported that immunosuppressive factors in the TME such as TGF- $\beta$ can promote Tconvs to differentiate into pTregs with TCR stimulation and the CNS1 enhancer, ${ }^{83}$ which facilitates TGF- $\beta$-dependent FOXP3 induction in an animal model.$^{84}$ Indoleamine 2,3-dioxygenase (IDO)-expressing myeloid cells might also promote the conversion of Tconvs to Tregs through an aryl hydrocarbon receptor (AHR) ${ }^{85}$ However, recent studies with human tumor samples have revealed that the overlap in TCR repertoires between intratumoral Tregs and Tconvs is limited, ${ }^{21} 76$ suggesting that Treg conversion is not a major source of tumor-infiltrating Tregs in humans. By contrast, tumor-resident Tregs react to mutated neoantigens and some immunogenic selfantigens in tumor cells, ${ }^{21}$ suggesting that thymus-derived tTregs undergo activation and clonal expansion in the TME in humans.

\section{SURVIVAL ADVANTAGE OF TREGS BASED ON METABOLIC ADAPTATIONS IN THE TME}

Effector $\mathrm{T}$ cells and Tregs employ different metabolic systems in normal vs inflammatory conditions, which has been increasingly highlighted (figures 2 and 3). ${ }^{80 ~ 86-88}$ TCR stimulation provokes a specific metabolic program through the phosphoinositide 3-kinase 
(PI3K)-mammalian target of rapamycin (mTOR) signaling pathway, leading to increased uptake of amino acids and glucose to enhance aerobic glycolysis. Activated effector $\mathrm{T}$ cells shift their metabolic program from oxidative phosphorylation (OXPHOS) to aerobic glycolysis, which is necessary for their survival and function, resulting in a competition for glucose between effector $\mathrm{T}$ cells and tumor cells in the TME ${ }^{89}$ Metabolic reprogramming in tumor cells changes the TME into a nutrientrestricted, lactate-rich, and hypoxic environment, which is unfavorable for the survival and function of effector T cells. ${ }^{90}$ However, Tregs can survive and retain their immunosuppressive function in such harsh conditions in the TME. FOXP3 plays an essential role in this distinct metabolic program of Tregs by suppressing glycolysis and promoting OXPHOS and nicotinamide adenine dinucleotide $\left(\mathrm{NAD}^{+}\right)$oxidation. As a result, Tregs can use lactate as an energy source. ${ }^{91}{ }^{92}$ While tumor-infiltrating non-Tregs convert pyruvate to lactate to produce $\mathrm{NAD}^{+}$to maintain glycolysis, Tregs in the TME convert pyruvate to acetyl-CoA in the mitochondria to trigger the tricarboxylic acid cycle, which provides a survival benefit to Tregs over other $\mathrm{T}$ cells, including effector $\mathrm{T}$ cells, in the lowglucose, high-extracellular lactate TME. ${ }^{91}$

In addition to lactate, fatty acids produced by tumor cells and stromal cells in the TME can be utilized by Tregs as an energy source for their survival and immunosuppressive function. Tregs use mechanisms in fatty acid metabolism, such as upregulating the fatty acid transporter CD $36^{93} 94$ and sterol-regulatory-element-binding protein signaling, ${ }^{95}$ to adapt to the fatty acid-rich TME. The oxidative metabolism of lipids in Tregs decreases their demand for glucose and leads to resistance to fatty acid-induced cellular toxicity. ${ }^{96}$ Accordingly, even in lowglucose conditions, Tregs use fatty acids for their proliferation and immunosuppressive function. ${ }^{80}{ }^{94}$ We have recently reported that $R H O A$ Y42 mutation in gastric cancer produces large amounts of fatty acids through upregulation of fatty acid synthase (FASN) compared with tumors without RHOA Y42 mutation, leading to more Tregs and fewer tumor-infiltrating $\mathrm{CD} 8^{+} \mathrm{T}$ cells in the TME, which contribute to impaired sensitivity to PD-1 blockade therapy. ${ }^{80}$

When nTregs are stimulated with TLR ligands in mice, glycolysis is increased through mTOR complex 1 (mTORC1) signaling, which promotes proliferation but reduces the immunosuppressive function of Tregs. ${ }^{86}$ In addition, migratory capacity is dependent on the upregulation of glycolysis through mTORC2, ${ }^{87}$ suggesting that Tregs potentially use glycolysis for proliferation and migration. On the other hand, the immunosuppressive function of Tregs was diminished in mice harboring Tregspecific depletion of mitochondrial complex III, which impairs OXPHOS. However, proliferation and survival were not affected in these mice. ${ }^{88} \mathrm{~A}$ similar phenotype was observed in mice with Treg-specific depletion of the metabolic sensor liver kinase B1, which results in lethal autoimmunity due to the disruption of mitochondrial metabolism. ${ }^{9798}$ Therefore, the immunosuppressive function of Tregs mainly depends on mitochondrial respiration and OXPHOS, which are regulated by FOXP3. The ability to use substrates from glycolysis or fatty acid oxidation provides Tregs with a functional and survival advantage in the TME. A direct relationship between glycolysis in tumor cells and intratumoral Treg stability has been demonstrated; glycolysis-low or defective tumors induce glycolysis in Tregs, resulting in functional destabilization of Tregs after CTLA-4 blockade therapy. ${ }^{99}$ This metabolic switch in Tregs is also found in a hypoxic environment. Hypoxia induces hypoxia-inducible factor (HIF)- $1 \alpha$ expression, which stimulates glycolysis in Tregs through the upregulation of the glucose transporter and glycolytic enzymes and suppression of mitochondrial respiration. ${ }^{93}$ HIF-1 $\alpha$-deficient Tregs have impaired migration but increased immunosuppressive function in mice with brain tumors. ${ }^{93}$

IDO expression induces the catabolism of tryptophan and synthesis of kynurenine, which suppresses antitumor immunity in the TME. The level of IDO expression in the TME is strongly correlated with an increased number of intratumoral Tregs. ${ }^{100}$ Kynurenine interacts with the ligand-activated transcription factor AHR, which increases the proliferation and immunosuppressive activity of Tregs. ${ }^{101} 102$

\section{TREATMENT-RELATED TREG ACCUMULATION AS AN ADAPTIVE IMMUNE RESISTANCE MECHANISM IN THE TME}

As described in previous sections, several mechanisms, including aberrant signaling in tumor cells based on gene alterations, can be involved in Treg recruitment into the TME before treatment (treatment-naive TME). On the other hand, treatments such as radiation therapy ${ }^{103}$ and CTLA-4 blocking antibodies ${ }^{104}$ promote the accumulation of Tregs in tumors, which is considered an adaptive immune resistance mechanism. Radiation therapy provides some favorable impacts on antitumor immunity through increasing antigen presentation and recruitment of cytotoxic immune cells, which is partly caused by DNA damage sensing through stimulator of interferon genes-dependent signaling. ${ }^{105}$ Tregs reportedly persist in the TME even after radiation therapy due to lower sensitivity to radiation than other lymphocytes, ${ }^{106}$ potentially leading to the development of an immunosuppressive TME in some types of cancer. ${ }^{107} 108$ Moreover, Treg depletion improved the sensitivity of tumors to radiation and inhibited metastasis in a preclinical model. ${ }^{109}$ Anti-CTLA-4 antibodies efficiently deplete Tregs through antibody-dependent cellular cytotoxicity (ADCC) in murine models, ${ }^{110}$ whereas the mechanism of action in patients remains controversial. Immunohistochemical analyses revealed that the number of Tregs increased after anti-CTLA-4 antibody treatment based on comparison of pre-treatment and post-treatment biopsy samples. ${ }^{111}$ Therefore, certain therapeutic interventions 
Table 1 Therapies that target Tregs approved by the FDA or being evaluated in clinical trials

\begin{tabular}{|c|c|c|}
\hline Name & Target & Clinical trial for solid tumors* \\
\hline \multicolumn{3}{|l|}{ Targeting immunosuppressive mechanisms } \\
\hline Ipilimumab & CTLA-4 & FDA approved \\
\hline Denileukin diftitox & CD25 (toxin conjugated) & FDA approved \\
\hline ADCT-301 & CD25 (ADC conjugated) & NCT03621982 \\
\hline RO7296682 & $\begin{array}{l}\text { CD25 (without IL-2 signal } \\
\text { blockade) }\end{array}$ & NCT04158583, NCT04642365 \\
\hline TTX-030, SRF617 & Ectonucleotidase CD39 & NCT03884556, NCT04336098 \\
\hline LY3475070, Sym024, CPI-006, MEDI9447 & Ectonucleotidase CD73 & $\begin{array}{l}\text { NCT04148937, NCT04672434, } \\
\text { NCT03454451, NCT02503774 }\end{array}$ \\
\hline PBF-509, ciforadenant, NIR178 & Adenosine receptor A2A & $\begin{array}{l}\text { NCT02403193, NCT02655822, } \\
\text { NCT03207867 }\end{array}$ \\
\hline Kinase inhibitors, ramucirumab & VEGFR2 & FDA approved \\
\hline IOA-244, AZD8186 & $\mathrm{PI} 3 \mathrm{~K} \delta$ & NCT04328844, NCT04001569 \\
\hline \multicolumn{3}{|c|}{ Targeting chemokine receptors and immune checkpoints } \\
\hline Mogamulizumab (KW-0761) & CCR4 & FDA approved \\
\hline FLX475 & CCR4 & NCT03674567 \\
\hline MEDI6469, PF-04518600, BMS 986178 & OX40 & NCT01862900, NCT02315066, NCT03831295 \\
\hline TRX518, BMS-986156, MEDI1873 & GITR & NCT01239134, NCT04021043, NCT02583165 \\
\hline JTX-2011, KY1044, GSK3359609 & ICOS & NCT02904226, NCT03829501, NCT02723955 \\
\hline \multicolumn{3}{|l|}{ Targeting metabolic adaptation } \\
\hline VT1021 & CD36 & NCT03364400 \\
\hline AZD3965 & MCT1 & NCT01791595 \\
\hline Epacadostat, NLG802, GDC-0919 & IDO & NCT01685255, NCT03164603, NCT02048709 \\
\hline
\end{tabular}

${ }^{*}$ Representative ongoing clinical trials that include both monotherapy and combination therapy. Includes clinical trials that are completed or recruiting participants.

ADC, antibody-drug conjugate; CTLA4, cytotoxic T lymphocyte antigen 4; FDA, Food and Drug Administration; GITR, glucocorticoid-induced TNF receptor; IDO, indoleamine 2,3-dioxygenase; IL-2, interleukin 2; MCT1, monocarboxylate transporter 1; PI3K, phosphoinositide 3-kinase; Tregs, regulatory T cells; VEGFR2, vascular endothelial growth factor receptor 2.

potentially enhance Tregs infiltration, which can impair the therapeutic outcome of subsequent treatments.

\section{TREATMENT STRATEGIES FOR HIGHLY SPECIFIC TREG- TARGETED THERAPIES}

Given that Treg abundance in the TME is dependent on distinct mechanisms in each patient, particularly inflamed and non-inflamed tumors, we need to consider the immunological profile of the TME in each patient. Importantly, an initial study of Treg-targeted treatment clearly demonstrated that Treg depletion induces tumor regression in some tumor cell lines, such as Meth $\mathrm{A}$ and RL-male 1 (BALB/c radiation leukemia), but not in others such as AKSL2 and RL-female $8,{ }^{112}$ indicating the importance of biomarkers for stratifying patients by the role that Treg suppression plays in tumor progression and survival when optimizing the clinical application of Treg-targeted therapy as immune precision medicine. Furthermore, when selecting the optimal treatment, the role of Tregs in the inflamed tumors or in non-inflamed tumors needs to be considered. Treg-targeted therapies discussed below (table 1) may be useful for both inflamed tumors and non-inflamed tumors. In particular, Tregs in non-inflamed tumors could be targeted with moleculartargeted therapy, given that they are generally recruited by specific mechanisms based on gene alterations, including EGFR and RHOA mutations in tumor cells.

\section{TARGETING IMMUNOSUPPRESSIVE MECHANISMS BY TREGS}

Anti-CTLA-4 monoclonal antibodies (mAbs) such as ipilimumab improve the immunological signature of the TME via Treg targeting. However, the detailed mechanism of action in clinical settings remains controversial. In mouse models, the antitumor immune responses induced by anti-CTLA-4 mAbs totally depend on the depletion of Tregs through Fc-mediated ADCC. ${ }^{110}$ In humans, while Treg depletion was not mainly involved in antitumor efficacy by ipilimumab, ${ }^{104111}$ potential contribution of Fc-mediated ADCC was shown. ${ }^{113}$ Bispecific antibodies that target two molecules highly expressed by intratumoral Tregs, CTLA- 4 and OX-40 or CTLA-4 and glucocorticoidinduced TNF receptor (GITR), had therapeutic effects 
in preclinical models. ${ }^{114} 115$ They might improve antitumor efficacy by efficiently depleting Tregs in humans. Targeting OX-40 and GITR will be discussed in the following section.

Since Tregs, especially intratumoral Tregs, express higher levels of CD25 than other effector T cells in human tumors, CD25 could be a crucial target for Treg depletion. Targeting CD25 expression by Tregs is therefore another option for modulating Treg function in the TME. Some therapeutic strategies targeting CD25 have been approved by the US Food and Drug Administration. For example, a fusion protein of IL-2 with diphtheria toxin, denileukin diftitox, is used in cutaneous $\mathrm{T}$ cell lymphoma. Although denileukin diftitox binds to CD25-expressing cells and kills them via the cytotoxic activity of diphtheria toxin, the efficacy for depleting Tregs was not sufficient in patients with melanoma. ${ }^{16}$ The novel anti-CD25 antibody RG6292 was developed to deplete Tregs selectively without disturbing IL-2 signaling in effector $\mathrm{T}$ cells ${ }^{117}$; it is under clinical evaluation (NCT04158583). Near-infrared photoimmunotherapy (NIR) targeting CD25 could also be a promising approach for local Treg depletion in tumors. NIR irradiation combined with an anti-CD25 antibody conjugated with a photoactivatable dye efficiently depleted Tregs in preclinical tumor models. ${ }^{118}$ In addition, ADCT-301, an antibody-drug conjugate against CD25, was developed for targeting CD25-expressing lymphomas. ${ }^{119}$ It might be used as another option to deplete Tregs in tumors; this approach is undergoing a clinical trial (NCT03621982).

Targeting adenosine production through the ectonucleotidases CD39 and CD73 expressed by Tregs can also be a promising target to augment antitumor immunity. Anti-CD39 and anti-CD73 antibodies that block ectonucleotidase activity, such as TTX-30, MEDI9447, and BMS-986179, are currently in clinical trials (NCT03884556, NCT03742102, and NCT02754141). In addition to inhibiting adenosine production, small molecule inhibitors of the adenosine receptor A2AR expressed by tumorinfiltrating T cells such as CPI-444, AZD4635, and PBF-509 prevent adenosine-dependent $\mathrm{T}$ cell suppression. Clinical trials for these inhibitors are underway (NCT02655822, NCT04089553, and NCT02403193).

VEGF receptor 2 (VEGFR2) is expressed by intratumoral Tregs, and VEGFA stimulation induced Treg proliferation in a preclinical model. ${ }^{120}$ We have shown that ramucirumab, an anti-VEGFR2 antibody, reduces the proliferation of eTregs in patients with gastric cancer. ${ }^{121}$ Thus, targeting the VEGFA-VEGFR2 axis might activate antitumor responses via reduction of Treg proliferation and infiltration in the TME.

Targeting FOXP3 to disrupt Tregs has also been attempted. AZD8701, an antisense oligonucleotide for FOXP3, partially reduced the expression of FOXP3 and its downstream transcriptional molecules in an in vitro experiment and humanized mouse models (https://
cancerres.aacrjournals.org/content/79/13_Supplement/2713). A clinical trial of AZD8701 is underway (NCT04504669).

Another option is targeting the distinct intrinsic signal dependency between Tregs and Tconvs, such as TCR signaling. ${ }^{122}$ The tyrosine kinase inhibitor imatinib inhibits the oncogenic breakpoint cluster region-abelson (BCR$\mathrm{ABL}$ ) protein and also has various off-targets including lymphocyte-specific protein tyrosine kinase (LCK), which plays an important role in TCR signaling. An analysis of patients with chronic myelogenous leukemia treated with imatinib uncovered selective depletion of eTregs. A therapeutic concentration of imatinib specifically induced apoptosis in eTregs, but not in effector T cells such as $\mathrm{CD}^{+} \mathrm{T}$ cells. Since Treg survival is heavily dependent on continuous stimulation from the TCR signal, ${ }^{123}$ inhibition of LCK by imatinib selectively induced Treg apoptosis. ${ }^{124}$ The PI3K signaling pathway is also essential for $\mathrm{T}$ cell survival and function. While PI3K $\delta$ isoform-specific PI3K inhibitor selectively depletes Tregs, the number of $\mathrm{CD} 8^{+}$ $\mathrm{T}$ cells is increased through PI3K $\delta$ specific inactivation in Tregs, resulting in the prevention of tumor progression and metastasis. ${ }^{125}{ }^{126}$ In fact, since Tregs and effector $\mathrm{T}$ cells such as $\mathrm{CD}^{+} \mathrm{T}$ cells have differences in PI3K $\delta$ dependency, the inhibitor could specifically target Tregs. Combination treatment consisting of the PI3K $\delta$ inhibitor INCB050465 and the anti-PD-1 mAb pembrolizumab is currently being studied in a clinical trial (NCT02646748).

\section{TARGETING CHEMOKINE RECEPTORS AND IMMUNE CHECKPOINT MOLECULES ON TREGS}

Inhibiting chemokine-dependent migration of Tregs into the TME can sensitize tumors to immunotherapies (table 1). The anti-CCR4 antibody mogamulizumab reduces the number of CCR $4^{+}$Tregs in patients with solid tumors. ${ }^{127} 128$ The depletion of Tregs was confirmed in patients treated with mogamulizumab plus an anti-PD-1 antibody (nivolumab) ${ }^{129}$ in a clinical trial, suggesting that this combination is a promising option in combination cancer immunotherapies. A small-molecule antagonist of CCR4, FLX475, is currently under evaluation in a phase I/II study as monotherapy and in combination with pembrolizumab in advanced cancers (https:// ascopubs.org/doi/abs/10.1200/JCO.2020.38.15_suppl. TPS3163) (NCT03674567). Blocking the CCL1-CCR8 axis is another option for Treg depletion in the TME. ${ }^{75}$ Two recent preclinical studies demonstrated that anti-CCR8 antibodies with Fc-dependent ADCC activity selectively deplete tumor-infiltrating Tregs due to prominent CCR8 expression by the activated Tregs in the TME, leading to long-lasting antitumor immune responses and synergistic antitumor effects with PD-1 blockade. ${ }^{130} 131$

Immune checkpoint molecules that are highly expressed by Tregs, such as OX40, GITR, and ICOS, could also be therapeutic targets. Several studies have shown that the stimulation of these receptors reduces the immunosuppressive function of Tregs, leading to the 
activation of effector T cells. ${ }^{132} 133$ Antibodies that act as agonists of OX40, such as MEDI6469 ${ }^{134}$ (NCT02274155), GITR, such as MK-4166 ${ }^{135}$ (NCT02132754), and ICOS, such as KY1044 ${ }^{136}$ (NCT03829501), are currently being investigated.

\section{TARGETING METABOLIC ADAPTATION OF TREGS TO THE TME}

Tregs can use free fatty acids and lactate, which provides metabolic advantage over effector T cells especially in the harsh-nutrient TME. To disturb the metabolic adaptation of Tregs, the fatty acid transporter CD36 and the lactate transporter monocarboxylate transporter 1 (MCT1), which are required for fatty acid and lactate uptake, respectively, can be important targets for reducing the number of Tregs and hampering their function in the TME. Inhibition of CD36 or MCT1 reduced Treg abundance in the TME and improved the sensitivity of PD-1 blockade in preclinical models. ${ }^{809294}$ In addition to targeting fatty acid uptake, blocking FASN with an acetyl-CoA carboxylase inhibitor (5-(tetradecyloxy)-2-furoic acid) and blocking fatty acid oxidation with a carnitine palmitoyltransferase 1a inhibitor, suppressed the proliferation and immunosuppressive function of Tregs. ${ }^{93} 137$ Elevated extracellular lactic acid levels reduce the function of effector $\mathrm{T}$ cells. Therefore, a lactate dehydrogenase A inhibitor can potentially rescue the effector function of $\mathrm{T}$ cells by reducing L-lactate production. ${ }^{91} 138$

Kynurenine produced with IDO activity on tryptophan, which interacts with AHR, increases the number of Tregs and tolerogenic myeloid cells in the TME. IDO-riched tumors have an activated AHR pathway, which is associated with resistance to PD-1 blockade. ${ }^{101}$ Targeting the IDOKynurenine-AHR axis could be a promising approach for improving the sensitivity of ICI by decreasing Tregs.

\section{CONCLUSIONS AND FUTURE DIRECTIONS}

The involvement of multiple mechanisms in Treg infiltration, activation, and survival in the TME has been revealed both in inflamed and non-inflamed tumors. The mix of mechanisms affecting Treg infiltration, activation, and survival in the TME might vary by patient. Gene alterations in tumor cells not only determine immunogenicity and inflammatory status but also contribute to the modulation of immune cell infiltration and survival in the TME, such as Treg infiltration based on chemokine profiles and Treg activation based on metabolic changes, which could be targeted by specific kinase inhibitors. Therefore, the mechanisms that mainly contribute to Treg abundance in the TME need to be characterized through both immunological and metabolic profiling based on gene alteration and targeted with immune precision therapy. Mechanism-based Treg-targeted therapy shows promise for improving current immunotherapies.

Correction notice This paper has been updated to amend author order. Collaborators Not applicable.

\section{Contributors SK and HN conceived and wrote the paper.}

Funding This study was supported by Grants-in-Aid for Scientific Research grant no. $17 \mathrm{H} 06162$ (to H.N.) and no. 21K07252 (to SK) from the Ministry of Education, Culture, Sports, Science and Technology of Japan, the Projects for Cancer Research by Therapeutic Evolution (P-CREATE; no. 16cm0106301h0001 to HN and no. $19 \mathrm{~cm} 0106335 \mathrm{~h} 0002$ to SK), the Development of Technology for Patient Stratification Biomarker Discovery grant (no. 19ae0101074s0401 to H.N.) from the Japan Agency for Medical Research and Development (AMED), and the National Cancer Center Research and Development Fund (no. 28-A-7 and 31-A-7 to HN).

Competing interests SK received research funding from Ono Pharmaceutical and Bristol-Myers Squibb outside this study. HN received honoraria and research funding from Ono Pharmaceutical, Chugai Pharmaceutical, MSD, and Bristol-Myers Squibb, and research funding from Taiho Pharmaceutical, Daiichi-Sankyo, Kyowa Kirin, Zenyaku Kogyo, Oncolys BioPharma, Debiopharma, Asahi-Kasei, Sysmex, Fujifilm, SRL, Astellas Pharmaceutical, Sumitomo Dainippon Pharma, and BD Japan outside this study.

Patient consent for publication Not required.

Provenance and peer review Not commissioned; externally peer reviewed.

Open access This is an open access article distributed in accordance with the Creative Commons Attribution 4.0 Unported (CC BY 4.0) license, which permits others to copy, redistribute, remix, transform and build upon this work for any purpose, provided the original work is properly cited, a link to the licence is given, and indication of whether changes were made. See https://creativecommons.org/ licenses/by/4.0/.

ORCID iD

Hiroyoshi Nishikawa http://orcid.org/0000-0001-6563-9807

\section{REFERENCES}

1 Dunn GP, Bruce AT, Ikeda $\mathrm{H}$, et al. Cancer immunoediting: from immunosurveillance to tumor escape. Nat Immunol 2002;3:991-8.

2 Wilky BA. Immune checkpoint inhibitors: the linchpins of modern immunotherapy. Immunol Rev 2019;290:6-23.

3 Sakaguchi S, Yamaguchi T, Nomura T, et al. Regulatory T cells and immune tolerance. Cell 2008;133:775-87.

4 Comito G, Iscaro A, Bacci M, et al. Lactate modulates CD4 ${ }^{+}$T-cell polarization and induces an immunosuppressive environment, which sustains prostate carcinoma progression via TLR8/miR21 axis. Oncogene 2019;38:3681-95.

5 Lim WC, Olding M, Healy E, et al. Human endothelial cells modulate $\mathrm{CD}^{+} \mathrm{T}$ cell populations and enhance regulatory $\mathrm{T}$ cell suppressive capacity. Front Immunol 2018;9:565.

6 Kieffer Y, Hocine HR, Gentric G, et al. Single-Cell analysis reveals fibroblast clusters linked to immunotherapy resistance in cancer. Cancer Discov 2020;10:1330-51.

7 Costa A, Kieffer Y, Scholer-Dahirel A, et al. Fibroblast heterogeneity and immunosuppressive environment in human breast cancer. Cancer Cell 2018;33:e10:463-79.

8 Saito $\mathrm{T}$, Nishikawa $\mathrm{H}$, Wada $\mathrm{H}$, et al. Two FOXP3 ${ }^{+} \mathrm{CD} 4^{+} \mathrm{T}$ cell subpopulations distinctly control the prognosis of colorectal cancers. Nat Med 2016;22:679-84.

9 Sautès-Fridman C, Petitprez F, Calderaro J, et al. Tertiary lymphoid structures in the era of cancer immunotherapy. Nat Rev Cancer 2019;19:307-25.

10 Saleh R, Elkord E. Foxp3+ T regulatory cells in cancer: prognostic biomarkers and therapeutic targets. Cancer Lett 2020;490:174-85.

11 Fontenot JD, Gavin MA, Rudensky AY. Foxp3 programs the development and function of $\mathrm{CD} 4^{+} \mathrm{CD} 25^{+}$regulatory T cells. Nat Immunol 2003;4:330-6.

12 Hori S, Nomura T, Sakaguchi S. Control of regulatory T cell development by the transcription factor FOXP3. Science 2003;299:1057-61.

13 Khattri R, Cox T, Yasayko S-A, et al. An essential role for Scurfin in $\mathrm{CD}^{+} \mathrm{CD}^{2} 5^{+} \mathrm{T}$ regulatory cells. Nat Immunol 2003;4:337-42.

14 Josefowicz SZ, Rudensky A. Control of regulatory T cell lineage commitment and maintenance. Immunity 2009;30:616-25.

15 Chen W, Jin W, Hardegen N, et al. Conversion of peripheral $\mathrm{CD} 4^{+} \mathrm{CD} 25^{-}$naive $\mathrm{T}$ cells to $\mathrm{CD} 4^{+} \mathrm{CD} 25^{+}$regulatory $\mathrm{T}$ cells by TGF-beta induction of transcription factor Foxp3. J Exp Med 2003;198:1875-86.

16 Curotto de Lafaille MA, Lafaille JJ. Natural and adaptive Foxp3+ regulatory T cells: more of the same or a division of labor? Immunity 2009;30:626-35. 
17 Feuerer M, Hill JA, Mathis D, et al. Foxp3+ regulatory T cells: differentiation, specification, subphenotypes. Nat Immunol 2009;10:689-95.

18 Mucida D, Park Y, Kim G, et al. Reciprocal Th17 and regulatory $T$ cell differentiation mediated by retinoic acid. Science 2007;317:256-60.

19 Ohkura N, Kitagawa Y, Sakaguchi S. Development and Maintenance of Regulatory T cells. Immunity 2013;38:414-23.

20 Zhou G, Levitsky HI. Natural regulatory T cells and de novo-induced regulatory $T$ cells contribute independently to tumor-specific tolerance. J Immunol 2007;178:2155-62.

21 Ahmadzadeh $\mathrm{M}$, Pasetto $\mathrm{A}$, Jia L, et al. Tumor-infiltrating human $\mathrm{CD}^{+}{ }^{+}$regulatory $\mathrm{T}$ cells display a distinct TCR repertoire and exhibit tumor and neoantigen reactivity. Sci Immunol 2019;4. doi:10.1126/ sciimmunol.aao4310. [Epub ahead of print: 11012019$]$

22 Tran DQ, Ramsey H, Shevach EM. Induction of FOXP3 expression in naive human CD4 ${ }^{+} \mathrm{FOXP} 3 \mathrm{~T}$ cells by T-cell receptor stimulation is transforming growth factor-beta dependent but does not confer a regulatory phenotype. Blood 2007;110:2983-90.

23 Miyara M, Yoshioka Y, Kitoh A, et al. Functional delineation and differentiation dynamics of human $\mathrm{CD}^{+} \mathrm{T}$ cells expressing the FOXP3 transcription factor. Immunity 2009;30:899-911.

24 Nishikawa H, Kato T, Tawara I, et al. Definition of target antigens for naturally occurring $\mathrm{CD} 4^{(+)} \mathrm{CD} 25^{(+)}$regulatory T cells. J Exp Med 2005:201:681-6.

25 Nishikawa H, Sakaguchi S. Regulatory T cells in tumor immunity. Int J Cancer 2010;127:759-67.

26 Nishikawa H, Sakaguchi S. Regulatory T cells in cancer immunotherapy. Curr Opin Immunol 2014;27:1-7.

27 Takahata $\mathrm{Y}$, Nomura A, Takada H, et al. CD25 ${ }^{+} \mathrm{CD} 4^{+} \mathrm{T}$ cells in human cord blood: an immunoregulatory subset with naive phenotype and specific expression of forkhead box p3 (Foxp3) gene. Exp Hematol 2004;32:622-9.

28 Qureshi OS, Zheng Y, Nakamura K, et al. Trans-endocytosis of CD80 and CD86: a molecular basis for the cell-extrinsic function of CTLA-4. Science 2011;332:600-3.

29 Onishi Y, Fehervari Z, Yamaguchi T, et al. Foxp3 ${ }^{+}$natural regulatory $T$ cells preferentially form aggregates on dendritic cells in vitro and actively inhibit their maturation. Proc Natl Acad Sci U S A 2008;105:10113-8.

30 Setoguchi R, Hori S, Takahashi T, et al. Homeostatic maintenance of natural Foxp $3^{+} \mathrm{CD} 25^{+} \mathrm{CD}^{+}$regulatory T cells by interleukin (IL)-2 and induction of autoimmune disease by IL-2 neutralization. J Exp Med 2005;201:723-35.

31 Levine AG, Arvey A, Jin W, et al. Continuous requirement for the TCR in regulatory T cell function. Nat Immunol 2014;15:1070-8.

32 Chinen T, Kannan AK, Levine AG, et al. An essential role for the IL-2 receptor in Treg cell function. Nat Immunol 2016;17:1322-33.

$33 \mathrm{Wu}$ Y, Borde M, Heissmeyer V, et al. Foxp3 controls regulatory T cell function through cooperation with NFAT. Cell 2006;126:375-87.

34 Ono M, Yaguchi H, Ohkura N, et al. Foxp3 controls regulatory T-cell function by interacting with AML1/RUNX1. Nature 2007;446:685-9.

35 Pandiyan $\mathrm{P}$, Zheng $\mathrm{L}$, Ishihara $\mathrm{S}$, et al. ${ }^{\mathrm{Cd} 4+\mathrm{Cd} 25+}{ }^{\mathrm{F}}{ } \mathrm{xpp}^{+}{ }^{+}$regulatory $\mathrm{T}$ cells induce cytokine deprivation-mediated apoptosis of effector CD4 ${ }^{+}$T cells. Nat Immunol 2007;8:1353-62.

36 Flavell RA, Sanjabi S, Wrzesinski SH, et al. The polarization of immune cells in the tumour environment by TGFbeta. Nat Rev Immunol 2010;10:554-67.

37 Gao Y, Souza-Fonseca-Guimaraes F, Bald T, et al. Tumor immunoevasion by the conversion of effector NK cells into type 1 innate lymphoid cells. Nat Immunol 2017;18:1004-15.

38 Gagliani N, Amezcua Vesely MC, Iseppon A, et al. Th17 cells transdifferentiate into regulatory $T$ cells during resolution of inflammation. Nature 2015;523:221-5.

39 Cuende J, Liénart S, Dedobbeleer O, et al. Monoclonal antibodies against GARP/TGF- $\beta 1$ complexes inhibit the immunosuppressive activity of human regulatory T cells in vivo. Sci Transl Med 2015;7:284ra56.

40 Cao X, Cai SF, Fehniger TA, et al. Granzyme B and perforin are important for regulatory $T$ cell-mediated suppression of tumor clearance. Immunity 2007;27:635-46.

41 Marie JC, Letterio JJ, Gavin M, et al. TGF-beta1 maintains suppressor function and Foxp3 expression in $\mathrm{CD} 4^{+} \mathrm{CD} 25^{+}$ regulatory T cells. J Exp Med 2005;201:1061-7.

42 Chen Y, Haines CJ, Gutcher I, et al. Foxp $3^{+}$Regulatory T Cells Promote T Helper 17 Cell Development In Vivo through Regulation of Interleukin-2. Immunity 2011;34:409-21.

43 Edwards JP, Hand TW, Morais da Fonseca D, et al. The GARP/ Latent TGF- $\beta 1$ complex on Treg cells modulates the induction of peripherally derived Treg cells during oral tolerance. Eur J Immunol 2016:46:1480-9.
44 Rubtsov YP, Rasmussen JP, Chi EY, et al. Regulatory T cell-derived interleukin-10 limits inflammation at environmental interfaces. Immunity 2008;28:546-58.

45 Turnis ME, Sawant DV, Szymczak-Workman AL, et al. Interleukin-35 limits anti-tumor immunity. Immunity 2016;44:316-29.

46 Sawant DV, Yano H, Chikina M, et al. Adaptive plasticity of IL$10^{+}$and IL- $35^{+}$Treg cells cooperatively promotes tumor $\mathrm{T}$ cell exhaustion. Nat Immunol 2019;20:724-35.

47 Morris AB, Farley CR, Pinelli DF, et al. Signaling through the Inhibitory Fc Receptor FcyRlIB Induces CD8 ${ }^{+} \mathrm{T}$ Cell Apoptosis to Limit T Cell Immunity. Immunity 2020;52:136-50.

48 Allard B, Longhi MS, Robson SC, et al. The ectonucleotidases CD39 and CD73: novel checkpoint inhibitor targets. Immunol Rev 2017;276:121-44.

49 Deaglio S, Dwyer KM, Gao W, et al. Adenosine generation catalyzed by CD39 and CD73 expressed on regulatory T cells mediates immune suppression. J Exp Med 2007;204:1257-65.

50 Borsellino G, Kleinewietfeld M, Di Mitri D, et al. Expression of ectonucleotidase CD39 by Foxp3 ${ }^{+}$Treg cells: hydrolysis of extracellular ATP and immune suppression. Blood 2007;110:1225-32.

51 Dosch M, Gerber J, Jebbawi F, et al. Mechanisms of ATP release by inflammatory cells. Int J Mol Sci 2018;19:1222.

52 Aswad F, Kawamura H, Dennert G. High sensitivity of $\mathrm{CD} 4^{+} \mathrm{CD} 25^{+}$ regulatory $T$ cells to extracellular metabolites nicotinamide adenine dinucleotide and ATP: a role for P2X7 receptors. J Immunol 2005; 175:3075-83.

53 Schenk U, Frascoli M, Proietti M, et al. Atp inhibits the generation and function of regulatory $T$ cells through the activation of purinergic P2X receptors. Sci Signal 2011;4:ra12.

54 Ohta A, Sitkovsky M. Extracellular adenosine-mediated modulation of regulatory T cells. Front Immunol 2014;5:304.

55 Rueda CM, Jackson CM, Chougnet CA. Regulatory T-cell-mediated suppression of conventional T-cells and dendritic cells by different cAMP intracellular pathways. Front Immunol 2016;7:216.

56 Sun X, Wu Y, Gao W, et al. CD39/ENTPD1 expression by $\mathrm{CD}^{+}{ }^{+} \mathrm{Foxp}^{+}$regulatory $\mathrm{T}$ cells promotes hepatic metastatic tumor growth in mice. Gastroenterology 2010;139:1030-40.

57 Stagg J, Divisekera U, Duret H, et al. CD73-deficient mice have increased antitumor immunity and are resistant to experimental metastasis. Cancer Res 2011;71:2892-900.

58 Maj T, Wang W, Crespo J, et al. Oxidative stress controls regulatory T cell apoptosis and suppressor activity and PD-L1-blockade resistance in tumor. Nat Immunol 2017:18:1332-41.

59 Kumagai S, Togashi Y, Kamada T, et al. The PD-1 expression balance between effector and regulatory $T$ cells predicts the clinical efficacy of PD-1 blockade therapies. Nat Immunol 2020;21:1346-58.

60 Kamada T, Togashi Y, Tay C, et al. PD $-1^{+}$regulatory T cells amplified by PD-1 blockade promote hyperprogression of cancer. Proc Natl Acad Sci U S A 2019;116:9999-10008.

61 Lee JC, Mehdizadeh S, Smith J, et al. Regulatory T cell control of systemic immunity and immunotherapy response in liver metastasis. Sci Immunol 2020;5:eaba0759.

62 Sugiyama D, Nishikawa H, Maeda Y, et al. Anti-CCR4 mAb selectively depletes effector-type FoxP $3^{+} \mathrm{CD} 4^{+}$regulatory $\mathrm{T}$ cells, evoking antitumor immune responses in humans. Proc Natl Acad Sci U S A 2013;110:17945-50.

63 Tan MCB, Goedegebuure PS, Belt BA, et al. Disruption of CCR5dependent homing of regulatory $T$ cells inhibits tumor growth in a murine model of pancreatic cancer. J Immunol 2009;182:1746-55.

64 De Simone M, Arrigoni A, Rossetti G, et al. Transcriptional landscape of human tissue lymphocytes unveils uniqueness of tumor-infiltrating T regulatory cells. Immunity 2016;45:1135-47.

65 Facciabene A, Peng X, Hagemann IS, et al. Tumour hypoxia promotes tolerance and angiogenesis via CCL28 and T(reg) cells. Nature 2011;475:226-30.

66 Gajewski TF, Corrales L, Williams J, et al. Cancer immunotherapy targets based on understanding the T Cell-Inflamed versus non-T Cell-Inflamed tumor microenvironment. Adv Exp Med Biol 2017;1036:19-31.

67 Spranger S, Spaapen RM, Zha Y, et al. Up-regulation of PD-L1, IDO, and T(regs) in the melanoma tumor microenvironment is driven by CD8(+) T cells. Sci Transl Med 2013;5:200ra116.

68 Curiel TJ, Coukos G, Zou L, et al. Specific recruitment of regulatory T cells in ovarian carcinoma fosters immune privilege and predicts reduced survival. Nat Med 2004;10:942-9.

69 Gobert M, Treilleux I, Bendriss-Vermare N, et al. Regulatory T cells recruited through CCL22/CCR4 are selectively activated in lymphoid infiltrates surrounding primary breast tumors and lead to an adverse clinical outcome. Cancer Res 2009:69:2000-9. 
70 Ménétrier-Caux C, Gobert M, Caux C. Differences in tumor regulatory T-cell localization and activation status impact patient outcome. Cancer Res 2009;69:7895-8.

71 Ishida T, Ishii T, Inagaki A, et al. Specific recruitment of CC chemokine receptor 4-positive regulatory T cells in Hodgkin lymphoma fosters immune privilege. Cancer Res 2006;66:5716-22.

72 de Oliveira CE, Gasparoto TH, Pinheiro CR, et al. CCR5-Dependent homing of T regulatory cells to the tumor microenvironment contributes to skin squamous cell carcinoma development. Mol Cancer Ther 2017;16:2871-80.

73 Shabaneh TB, Molodtsov AK, Steinberg SM, et al. Oncogenic BRAF V600E Governs Regulatory T-cell Recruitment during Melanoma Tumorigenesis. Cancer Res 2018;78:5038-49.

74 Islam SA, Ling MF, Leung J, et al. Identification of human CCR8 as a CCL18 receptor. J Exp Med 2013;210:1889-98.

75 Barsheshet Y, Wildbaum G, Levy E. CCR8 ${ }^{+}$FOXP3 ${ }^{+}$Treg cells as master drivers of immune regulation. Proc Natl Acad Sci U S A 2017; 114:6086-91.

76 Plitas G, Konopacki C, Wu K, et al. Regulatory T cells exhibit distinct features in human breast cancer. Immunity 2016;45:1122-34

77 Rahma OE, Hodi FS. The intersection between tumor angiogenesis and immune suppression. Clin Cancer Res 2019;25:5449-57.

78 Kumagai S, Koyama S, Nishikawa H. Antitumour immunity regulated by aberrant ErbB family signalling. Nat Rev Cancer 2021;21:181-97.

79 Sugiyama $\mathrm{E}$, Togashi $\mathrm{Y}$, Takeuchi $\mathrm{Y}$, et al. Blockade of EGFR improves responsiveness to PD-1 blockade in EGFR-mutated non-small cell lung cancer. Sci Immunol 2020;5. doi:10.1126/ sciimmunol.aav3937. [Epub ahead of print: 31012020$].$

80 Kumagai S, Togashi Y, Sakai C, et al. An oncogenic alteration creates a microenvironment that promotes tumor progression by conferring a metabolic advantage to regulatory $\mathrm{T}$ cells. Immunity 2020;53:187-203

81 Jiang $\mathrm{H}$, Hegde S, Knolhoff BL, et al. Targeting focal adhesion kinase renders pancreatic cancers responsive to checkpoint immunotherapy. Nat Med 2016;22:851-60.

82 Serrels A, Lund T, Serrels B, et al. Nuclear FAK controls chemokine transcription, Tregs, and evasion of anti-tumor immunity. Cell 2015;163:160-73.

83 Zheng $Y$, Josefowicz S, Chaudhry A, et al. Role of conserved noncoding DNA elements in the FOXP3 gene in regulatory T-cell fate. Nature 2010;463:808-12.

84 Samstein RM, Arvey A, Josefowicz SZ, et al. Foxp3 exploits a pre-existent enhancer landscape for regulatory $\mathrm{T}$ cell lineage specification. Cell 2012;151:153-66.

85 Curti A, Pandolfi S, Valzasina B, et al. Modulation of tryptophan catabolism by human leukemic cells results in the conversion of CD25 into CD25 ${ }^{+}$T regulatory cells. Blood 2007:109:2871-7.

86 Gerriets VA, Kishton RJ, Johnson MO, et al. Foxp3 and Tolllike receptor signaling balance $\mathrm{T}_{\text {r c }}$ cell anabolic metabolism for suppression. Nat Immunol 2016;17:1459-66.

87 Kishore M, Cheung KCP, Fu H, et al. Regulatory T cell migration is dependent on Glucokinase-Mediated glycolysis. Immunity 2017;47:e10:875-89.

88 Weinberg SE, Singer BD, Steinert EM, et al. Mitochondrial complex III is essential for suppressive function of regulatory T cells. Nature 2019;565:495-9.

89 Wang A, Luan HH, Medzhitov R. An evolutionary perspective on immunometabolism. Science 2019;363:eaar3932.

90 Buck MD, Sowell RT, Kaech SM, et al. Metabolic instruction of immunity. Cell 2017:169:570-86

91 Angelin A, Gil-de-Gómez L, Dahiya S, et al. Foxp3 reprograms T cell metabolism to function in low-glucose, High-Lactate environments. Cell Metab 2017;25:1282-93.

92 Watson MJ, Vignali PDA, Mullett SJ, et al. Metabolic support of tumour-infiltrating regulatory $T$ cells by lactic acid. Nature 2021;591:645-51.

93 Miska J, Lee-Chang C, Rashidi A, et al. HIF-1 $\alpha$ Is a Metabolic Switch between Glycolytic-Driven Migration and Oxidative Phosphorylation-Driven Immunosuppression of Tregs in Glioblastoma. Cell Rep 2019;27:226-37.

94 Wang H, Franco F, Tsui Y-C, et al. Cd36-Mediated metabolic adaptation supports regulatory $\mathrm{T}$ cell survival and function in tumors. Nat Immunol 2020;21:298-308.

95 Lim SA, Wei J, Nguyen T-LM, et al. Lipid signalling enforces functional specialization of $T_{\text {reg }}$ cells in tumours. Nature 2021:591:306-11.

96 Howie D, Cobbold SP, Adams E, et al. Foxp3 drives oxidative phosphorylation and protection from lipotoxicity. JCl Insight 2017;2:e89160.
97 He N, Fan W, Henriquez B, et al. Metabolic control of regulatory T cell (Treg) survival and function by LKB1. Proc Natl Acad Sci U S A 2017;114:12542-7.

98 Yang K, Blanco DB, Neale G, et al. Homeostatic control of metabolic and functional fitness of Treg cells by LKB1 signalling. Nature 2017;548:602-6.

99 Zappasodi R, Serganova I, Cohen IJ, et al. CTLA-4 blockade drives loss of $T_{\text {reg }}$ stability in glycolysis-low tumours. Nature 2021;591:652-8.

100 Godin-Ethier J, Hanafi L-A, Piccirillo CA, et al. Indoleamine 2,3-dioxygenase expression in human cancers: clinical and immunologic perspectives. Clin Cancer Res 2011;17:6985-91.

101 Campesato LF, Budhu S, Tchaicha J, et al. Blockade of the AhR restricts a Treg-macrophage suppressive axis induced by Lkynurenine. Nat Commun 2020;11:4011.

102 Mezrich JD, Fechner JH, Zhang X, et al. An interaction between kynurenine and the aryl hydrocarbon receptor can generate regulatory T cells. J Immunol 2010;185:3190-8.

103 Barker HE, Paget JTE, Khan AA, et al. The tumour microenvironment after radiotherapy: mechanisms of resistance and recurrence. Nat Rev Cancer 2015;15:409-25.

104 Sharma A, Subudhi SK, Blando J, et al. Anti-CTLA-4 Immunotherapy Does Not Deplete FOXP3 ${ }^{+}$Regulatory T Cells (Tregs) in Human Cancers. Clin Cancer Res 2019;25:1233-8.

105 McLaughlin M, Patin EC, Pedersen M, et al. Inflammatory microenvironment remodelling by tumour cells after radiotherapy. Nat Rev Cancer 2020;20:203-17.

106 Qu Y, Zhang B, Liu S, et al. 2-Gy whole-body irradiation significantly alters the balance of $\mathrm{CD} 4^{+} \mathrm{CD} 25-\mathrm{T}$ effector cells and $\mathrm{CD} 4^{+} \mathrm{CD} 25^{+} \mathrm{Foxp}^{+} \mathrm{T}$ regulatory cells in mice. Cell Mol Immunol 2010;7:419-27.

107 Schuler PJ, Harasymczuk M, Schilling B, et al. Effects of adjuvant chemoradiotherapy on the frequency and function of regulatory T cells in patients with head and neck cancer. Clin Cancer Res 2013;19:6585-96.

108 Qinfeng S, Depu W, Xiaofeng Y, et al. In situ observation of the effects of local irradiation on cytotoxic and regulatory T lymphocytes in cervical cancer tissue. Radiat Res 2013;179:584-9.

$109 \mathrm{Ji}$ D, Song C, Li Y, et al. Combination of radiotherapy and suppression of Tregs enhances abscopal antitumor effect and inhibits metastasis in rectal cancer. $J$ Immunother Cancer 2020;8:e000826.

110 Simpson TR, Li F, Montalvo-Ortiz W, et al. Fc-Dependent depletion of tumor-infiltrating regulatory T cells co-defines the efficacy of anti-CTLA-4 therapy against melanoma. J Exp Med 2013;210:1695-710.

111 Sharma A, Subudhi SK, Blando J, et al. Anti-CTLA-4 Immunotherapy Does Not Deplete FOXP3 ${ }^{+}$Regulatory $T$ Cells (Tregs) in Human Cancers-Response. Clin Cancer Res 2019;25:3469-70.

112 Onizuka S, Tawara I, Shimizu J, et al. Tumor rejection by in vivo administration of anti-CD25 (interleukin-2 receptor alpha) monoclonal antibody. Cancer Res 1999:59:3128-33.

113 Arce Vargas F, Furness AJS, Litchfield K, et al. Fc effector function contributes to the activity of human anti-CTLA-4 antibodies. Cancer Cell 2018;33:649-63.

114 Kvarnhammar AM, Veitonmäki N, Hägerbrand K, et al. The CTLA-4 $X$ OX40 bispecific antibody ATOR-1015 induces anti-tumor effects through tumor-directed immune activation. J Immunother Cancer 2019;7:103

115 Millán-Pérez Peña L, Martin P-S, Herrera-Camacho I, et al. Colon carcinoma treatment using bispecific anti-GITR/CTLA-4 antibodies: a patent evaluation of WO2018091739. Expert Opin Ther Pat 2020;30:307-11.

116 Luke JJ, Zha Y, Matijevich K, et al. Single dose denileukin diftitox does not enhance vaccine-induced $T$ cell responses or effectively deplete Tregs in advanced melanoma: immune monitoring and clinical results of a randomized phase II trial. J Immunother Cancer 2016:4:35.

117 Solomon I, Amann M, Goubier A, et al. CD25-T - depleting antibodies preserving IL-2 signaling on effector T cells enhance effector activation and antitumor immunity. Nat Cancer 2020;1:1153-66.

118 Sato K, Sato N, Xu B, et al. Spatially selective depletion of tumor-associated regulatory T cells with near-infrared photoimmunotherapy. Sci Transl Med 2016;8:352ra110.

119 Flynn MJ, Zammarchi F, Tyrer PC, et al. ADCT-301, a pyrrolobenzodiazepine (PBD) dimer-containing antibody-drug conjugate (ADC) targeting CD25-Expressing hematological malignancies. Mol Cancer Ther 2016;15:2709-21. 
120 Terme M, Pernot S, Marcheteau E, et al. VEGFA-VEGFR pathway blockade inhibits tumor-induced regulatory T-cell proliferation in colorectal cancer. Cancer Res 2013;73:539-49.

121 Tada Y, Togashi Y, Kotani D, et al. Targeting VEGFR2 with Ramucirumab strongly impacts effector/ activated regulatory $T$ cells and $\mathrm{CD} 8^{+} \mathrm{T}$ cells in the tumor microenvironment. $\mathrm{J}$ Immunother Cancer 2018:6:106.

122 Moran AE, Holzapfel KL, Xing Y, et al. T cell receptor signal strength in Treg and iNKT cell development demonstrated by a novel fluorescent reporter mouse. J Exp Med 2011;208:1279-89.

123 Vahl JC, Drees C, Heger K, et al. Continuous T cell receptor signals maintain a functional regulatory $\mathrm{T}$ cell pool. Immunity 2014;41:722-36.

124 Tanaka A, Nishikawa H, Noguchi S, et al. Tyrosine kinase inhibitor imatinib augments tumor immunity by depleting effector regulatory T cells. J Exp Med 2020;217

125 Ali K, Soond DR, Pineiro R, et al. Inactivation of $\mathrm{Pl}(3) \mathrm{K}$ p110 1 breaks regulatory T-cell-mediated immune tolerance to cancer. Nature 2014;510:407-11.

126 Ahmad S, Abu-Eid R, Shrimali R, et al. Differential PI3K Signaling in CD4 ${ }^{+}$T-cell Subsets Enables Selective Targeting of T Regulatory Cells to Enhance Cancer Immunotherapy. Cancer Res 2017;77:1892-904

$127 \mathrm{Ni} \mathrm{X}$, Jorgensen JL, Goswami M, et al. Reduction of regulatory T cells by Mogamulizumab, a defucosylated anti-CC chemokine receptor 4 antibody, in patients with aggressive/refractory mycosis fungoides and Sézary syndrome. Clin Cancer Res 2015;21:274-85.

128 Kurose K, Ohue Y, Wada H, et al. Phase la Study of FoxP3 ${ }^{+}$CD4 Treg Depletion by Infusion of a Humanized Anti-CCR4 Antibody, KW-0761, in Cancer Patients. Clin Cancer Res 2015;21:4327-36.

129 Doi T, Muro K, Ishii H, et al. A phase I study of the Anti-CC chemokine receptor 4 antibody, Mogamulizumab, in combination with nivolumab in patients with advanced or metastatic solid tumors. Clin Cancer Res 2019;25:6614-22.
130 Van Damme H, Dombrecht B, Kiss M, et al. Therapeutic depletion of $\mathrm{CCR}^{+}$tumor-infiltrating regulatory $\mathrm{T}$ cells elicits antitumor immunity and synergizes with anti-PD-1 therapy. J Immunother Cancer 2021:9:e001749.

131 Campbell JR, McDonald BR, Mesko PB, et al. Fc-optimized AntiCCR8 antibody depletes regulatory $T$ cells in human tumor models. Cancer Res 2021;81:2983-94.

132 Shimizu J, Yamazaki S, Takahashi T, et al. Stimulation of $\mathrm{CD} 25^{+} \mathrm{CD} 4^{+}$regulatory $\mathrm{T}$ cells through GITR breaks immunological self-tolerance. Nat Immunol 2002;3:135-42.

133 Piconese S, Valzasina B, Colombo MP. Ox40 triggering blocks suppression by regulatory $T$ cells and facilitates tumor rejection. $J$ Exp Med 2008;205:825-39.

134 Duhen R, Ballesteros-Merino C, Frye AK, et al. Neoadjuvant anti-OX40 (MEDI6469) therapy in patients with head and neck squamous cell carcinoma activates and expands antigen-specific tumor-infiltrating T cells. Nat Commun 2021;12:1047.

135 Sukumar S, Wilson DC, Yu Y, et al. Characterization of MK-4166, a clinical agonistic antibody that targets human GITR and inhibits the generation and suppressive effects of T regulatory cells. Cancer Res 2017;77:4378-88.

136 Sainson RCA, Thotakura AK, Kosmac M, et al. An antibody targeting ICOS increases intratumoral cytotoxic to regulatory T-cell ratio and induces tumor regression. Cancer Immunol Res 2020;8:1568-82.

137 Pacella I, Procaccini C, Focaccetti C, et al. Fatty acid metabolism complements glycolysis in the selective regulatory $\mathrm{T}$ cell expansion during tumor growth. Proc Natl Acad Sci U S A 2018;115:E6546-55.

138 Hermans D, Gautam S, García-Cañaveras JC, et al. Lactate dehydrogenase inhibition synergizes with IL-21 to promote CD8 ${ }^{+}$ T cell stemness and antitumor immunity. Proc Natl Acad Sci U S A 2020;117:6047-55 
Correction: Mechanisms of regulatory $T$ cell infiltration in

tumors: implications for innovative immune

\section{precision therapies}

Koyama S, Nishikawa H. Mechanisms of regulatory T cell infiltration in tumors: implications for innovative immune precision therapies. J Immunother Cancer 2021;9:e002591. doi: 10.1136/jitc-2021-002591

This paper has been updated to amend author order.

Open access This is an open access article distributed in accordance with the Creative Commons Attribution 4.0 Unported (CC BY 4.0) license, which permits others to copy, redistribute, remix, transform and build upon this work for any purpose, provided the original work is properly cited, a link to the licence is given, and indication of whether changes were made. See https://creativecommons.org/licenses/by/4.0/.

(C) Author(s) (or their employer(s)) 2021. Re-use permitted under CC BY. Published by BMJ.

J Immunother Cancer 2021;9:e002591corr1. doi:10.1136/jitc-2021-002591corr1

A) Check for updates 